\title{
EFFECT OF INLET PLENUM ON HEAT TRANSFER IN FRACTAL MICRO CHANNELS
}

\author{
GURJIT SINGH \& DR. S.S. SEHAGAL
}

Mechanical Engineering, Chandigarh University, Gharuan, India

\begin{abstract}
The computational analysis for Microchannel flow in branched network was investigated three dimensional CFD approach. The effect of the change of Inlet Plenum size at constant Aspect Ratio (AR) of the outermost channel on heat transfer in fractal branched micro channel was performed. The properties are cosidred along a particular path along the bifurcated path has considerably effected by Inlet plenum size. Velocity in the inner channel after straight run have reduced significantly even for same AR and Reynolds Number (Re). This leads to the conclusion that IP size effects the velocity after the bifurcation. Due to this effect of inlet plenum size flow patterns change along the flow path which leads to significant change in convective coefficient $h$ and ultimately Nusselts number. Average Nusselts number also observed more that already peported results in the research.
\end{abstract}

KEYWORDS: Microchannel, Velocity, Inlet Plenum

Received: Jun 08, 2020; Accepted: Jun 28, 2020; Published: Sep 10, 2020; Paper Id.: IJMPERDJUN20201145

\section{INTRODUCTION}

Transistor are the building block of our day to day digital life and are continuously forced to occupy less and less space with more and more count, their heat flow methods are becoming less effective. They are not capable to carry heavy amount of heat generated by these transistors. These thermal issues are becoming increasingly important for reliable working of wide variety of integrated circuits. High power densities give rise to higher junction temperatures. This high temperature is the major cause of semiconductor device failure. Straight parallel micro channels are one such solution to enhance cooling capacity of heat exchangers. These channels increase total convective area, which further contributes to enhance the convective coefficient. This technique also carries some drawbacks with it such as high pressure drop and uneven temperature distribution. This non uniform temperature gradient results in thermal stress, which could alter electronic properties and could lead to damage of the device.

This idea of cooling with Straight channels came a long since it's conception by Tuckerman and Pease [1]. Lee et al [2] established that classical correlations are equally valid for macro as well as microchannel flow predictions. Medawar [3] et al also presented good agreement between experimental and theoretical results based on conventional energy and Navier Stroke equations.

Nature is always a source of inspiration. Fractal networks (branching) and non fractal networks exist in nature and works optimally. In their work west et al used power law and shown that circulatory system is perfect example of Fractal system [4][5]. The blood flow in artery or vein is entirely laminar having Re less than 1000[ ]. Pence et al [7] assumed that thermal and metabolic system are analogous and branching pattern can be used in to analyze transportation ( thermal and fluidic) processes in micro fluidic systems. Cheng et al[8] also backed the idea of adapting branched structured from nature by showing that it has more heat transfer capacity and less power 
consumption as compare to the traditional straight method. The constructal theory proposed by Bejan [9] for any flow will take a path of least resistance and analyzed it for transportation networks that emerged from one source and then occupy the whole flow domain. Pence at al [10] compared the fractal design flow parameter with straight flow microchannel. They also verified the basic assumptions made that boundary layer is reinitiated at each bifurcation level. Bejan et al [9][11][12] first did geometric optimization of a parallel plate and round tube channels, based on the constructal theory also . He also demonstrated that for a disc shaped system bifurcation from one to two channels instead of three or higher is more desirable as for higher order bifurcation design become complex and difference of desired properties between these complex models become small. Pence at al [13] [14] suggested that for disc shape the bifurcation angle's role in global pressure drop is significant. Inlet plenum size provides a constrain to maximum number of channels emerging from inlet plenum and can effect output parameters. In the straight channels Sehgal et al [15] had shown that aspect ratio of the channel inlet plenum reduce pressure drop in straight channels. No such knowledge regarding relation of Inlet plenum and outermost channel Aspect ratio with flow parameters in fractal shape channel is available.

In the purposed work a nature inspired branched flow is analyzed. It will be interesting to know that how well a heat sink based upon this kind of design will perform in cooling of electronic microprocessors. Following flow network is purposed as shown in figure 1. It is known that in comparison to straight microchannel heat sinks with fixed convective area (wall area), for identical flow rate, the pressure drop and temperature gradient along the branching network are smaller in single phase flow. This fractal like branching flow network mimics flow distribution found in nature.

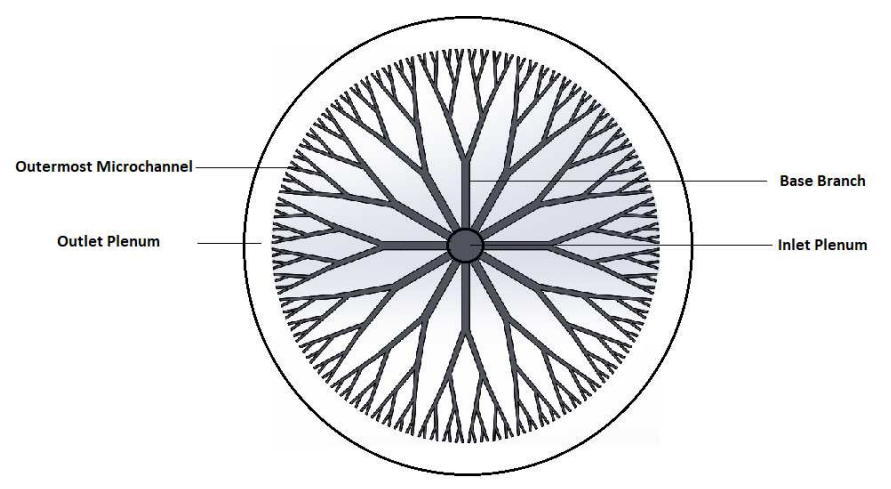

Figure 1: Fractal Like Branched Micro Channel Flow Network.

\section{METHOD}

Fractal shapes exist extensively and working efficiently in nature, where fluid flow and heat rejection are required with minimum flow resistance, such as flow fluid and heat transfer in plants leave, web of veins to carry blood in human body etc. Pence [6] proposed a circular heat exchanger inspired by these fractal entities. This flow arrangement consist fractal shaped micro channels having characteristics, governed by the scaling laws given in [4]. Following are scaling diameter ratio and length ratio (guiding the branching dimensions).

$$
\begin{aligned}
& \beta=\frac{d k+1}{d \mathbf{k}}=\mathrm{n}^{-1 / 3} \\
& \gamma=\frac{L k+1}{L k}=n^{-1 / 2}
\end{aligned}
$$

A full disk shape microchannel heat sink have many symmetric and similar microchannels. We are assuming that these all have same flow patterns. So one such microchannel is investigated shown in the figure 2 . Here d, L are hydraulic 
diameter and length of the micro channels respectively. Each microchannel branch is further bifurcated into two new branches and this is represented by $\mathrm{n}=2$. Order of the branch at the bifurcation is represented by subscript $\mathrm{k} . \mathrm{k}$ and $\mathrm{k}+1$ represent lower and higher order branched channels. The channel emerging from circular Inlet Plenum is base channel and is zero order branch. This will be represented by $\mathrm{k}=0$. Direction of flow is a from inlet plenum to outlet plenum. Flow is bifurcated four times then reaches to the outlet plenum by 16 channels. The $\mathrm{R}_{\mathrm{IP}}$ is the Inlet plenum radius and size of the whole heat sink is fixed by distance between center of inlet plenum and outer boundary of outlet plenum represented by R. Any change in inlet plenum diameter will be simultaneously reflected in size of outlet plenum. Length of microchannel is measured radialy as shown in figure 1 . For $\mathrm{k} \geq 1$ channel is bifurcated asymmetrically.

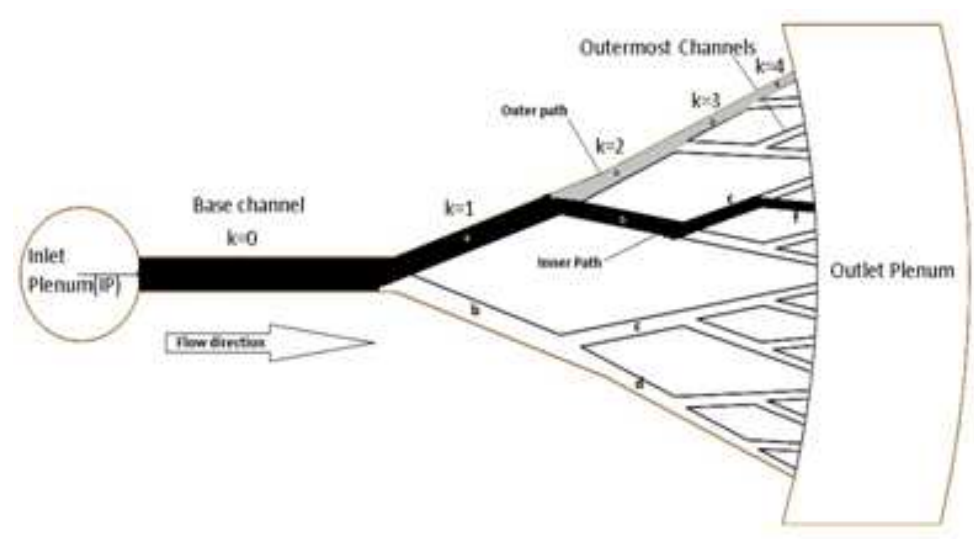

Figure 2: Shape and Flow Path of Cooling Fluid.

In the present study effect of inlet plenum size on temperature profile, convectice coefficient and Nusselts number in fractal microchannel is analyzed using three dimensional CFD analyses. Ansys fluent is used for this purpose and results are validated by work of Pence [7] and experimental flow analysis. Dimensions of the network are given in the following tables with changing aspect ratio of outer most channels by changing channel depth $(\mathrm{H})$ and keeping width constant due to physical constrains of the machine. $\mathrm{H}$ is constant throughout one type of model. Inlet Plenum aspect ratio is changed keeping total distance between Inlet plenum center and outer wall of outlet plenum constant. Water is used as a working fluid. This whole arrangement is studied for fixed Reynolds numbers at the entry if zeroth level branch. A heat flux of 100 $\mathrm{W} / \mathrm{cm}^{2}$ is also applied to heat sink include the effect of temperature rise on the thermal properties properties.

Table 1: Dimensions of Work Pieces $(\mathrm{AR}=4)$

\begin{tabular}{|c|c|c|c|c|c|}
\hline Level (k) & H & $\mathbf{w}$ & $\mathbf{D}$ & $\mathbf{L}$ & AR \\
\hline 0 & 1 & 1.016 & 1.008 & 8.000 & 1.0 \\
\hline 1 & 1 & 0.667 & 0.800 & 5.657 & 1.5 \\
\hline 2 & 1 & 0.465 & 0.635 & 4.000 & 2.1 \\
\hline 3 & 1 & 0.337 & 0.504 & 2.828 & 3.0 \\
\hline 4 & 1 & 0.250 & 0.400 & 2.000 & $\mathbf{4}$ \\
\hline
\end{tabular}

Table 2: Working Parameters

\begin{tabular}{|c|c|c|}
\hline Aspect Ratio & Re Inelt Ch & IP Radius(mm) \\
\hline 4 & 2000 & 2 \\
\hline 4 & 2000 & 3 \\
\hline 4 & 2000 & 4 \\
\hline
\end{tabular}

This analysis had taken place at $300 \mathrm{~K}$ room temperature and water outlet of the heat sink is kept open to atmospheric temperature. 


\section{3-D CFD Analysis}

Commercially available Simulation tool ANSYS Fluent is used to analyze. 3D computational fluid dynamics is performed by finite volume method based discretization approach. In this study 3D energy, momentum and continuity equations under steady and incompressible conditions are used to predict the flow environment.

Continuity Equation

$$
\frac{\partial V_{i}}{\partial x_{i}}=0
$$

Momentum Equation

$$
\rho\left(\frac{\partial\left(V_{i} V_{j}\right)}{\partial x_{i}}\right)=\frac{\partial}{\partial x_{i}}\left(\mu \frac{\partial V_{j}}{\partial x_{i}}\right)-\frac{\partial p}{\partial x_{i}}
$$

Energy Equation

$$
\frac{\partial(\rho h)}{\partial \dot{t}}+\frac{\partial\left(\rho u_{i} h\right)}{\partial x_{i}}=-\frac{\partial p}{\partial \dot{t}}+\frac{\partial}{\partial x_{i}}\left[\frac{k}{c_{p}} \frac{\partial h}{\partial x_{i}}-\dot{q}_{i}^{R}\right]
$$

In this study SIMPLE approach is used to for pressure velocity coupling. To reduce the errors due to mesh second order accuracy is applied. Under-relaxation factors of 0.2, 0.7, 0.95 are applied for pressure, momentum and energy respectively. Slandered convergence criteria is applied. Bulk water temperature $0 \mathrm{f} 300 \mathrm{~K}$ is used at the inlet plenum. Flow conditions are assumed laminar at base channel entrance from the inlet plenum. No slip and impermeable flow conditions are assumed at walls. Mass flow rate is fixed at Inlet plenum entrance and Re number is assumed at beginning of $\mathrm{k}=0$ channel.

\section{RESULTS AND DISCUSSION}

3D Study of fluid flow model is made and the results were compared with the earlier Pence [7] for validation of the work with smaller dimensions than the present work. Garimella concluded that existing fluid flow laws are valid for small scale and large scale flow so scaling does not affect the properties. In the same model with different control variables, fluid flow is assumed laminar but within that regime fixed 2000 Reynolds number range were investigated. In these arrangements the pressure distribution is not decreasing smoothly over the whole length of channel but continuously changing after smooth and steep decrease at the inlet of base channel from inlet plenum. For fixed aspect ratio and fixed Re the pressure distribution is remaining almost unchenged. In figure 2 investigated fluid flow branch is highlighted and all the properties are measured along this highlighted line from inlet plenum to the outer channels.

Fluid enter channel through Inlet plenum. Three different Inlet plenum sizes (radius 2,3,4mm) for models M42A, M43A and M44A. It is noticeable that in only varying factor is inlet plenum radius. All other parameters are fixed at the first value. 

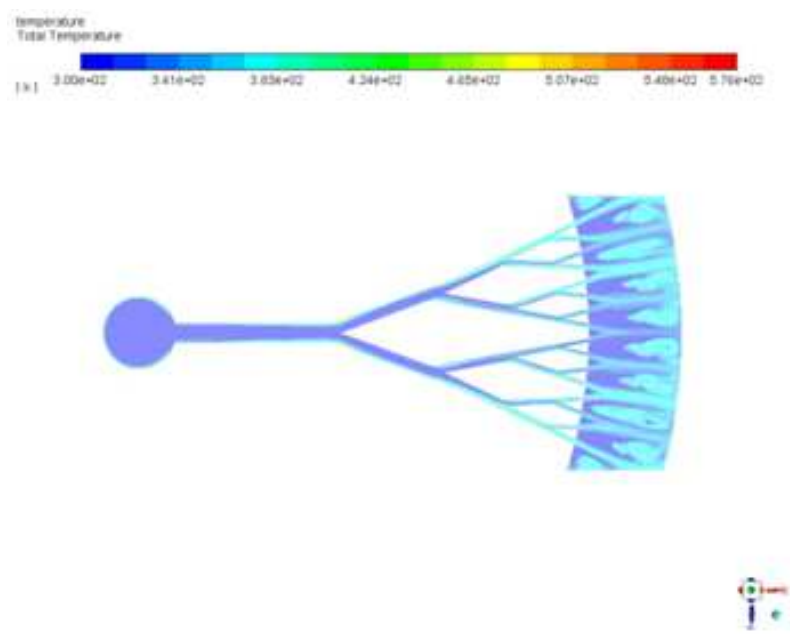

Figure 3: Temperature Contours for M42A.
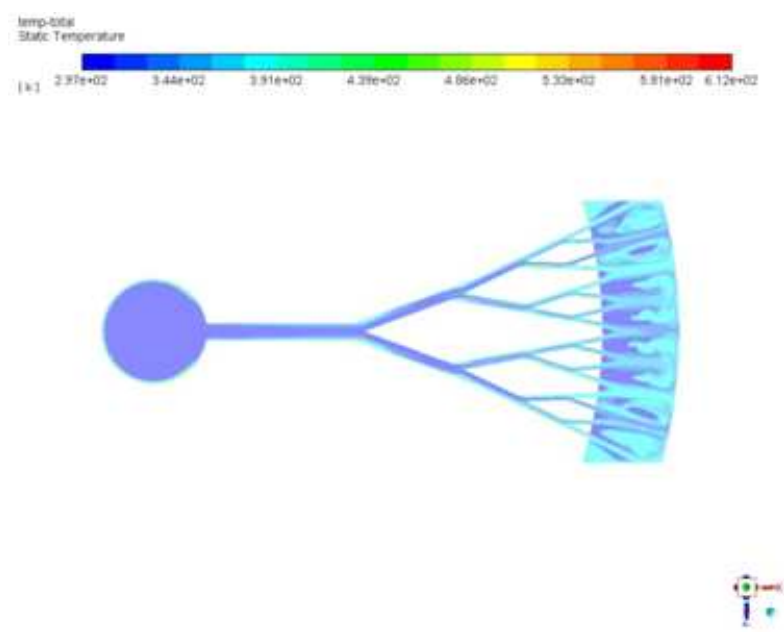

Figure 4: Temperature Contours for M43A.<smiles>C#CC</smiles>

in: 3
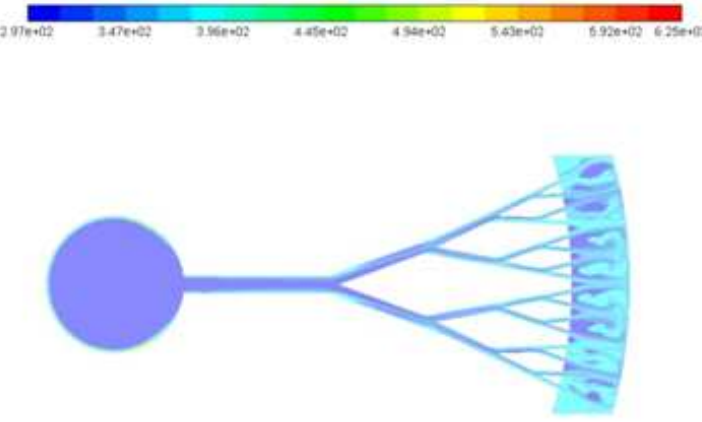

Figure 5: Temperature Contours for M43A.

Different temperature profiles are obtained and we can see the difference in temperature profiles in base branch and bifurcated branches. Temperature profile for all the three sets along shaded microchannel is calculated and following plot is obtained as shown in figure 5 . 


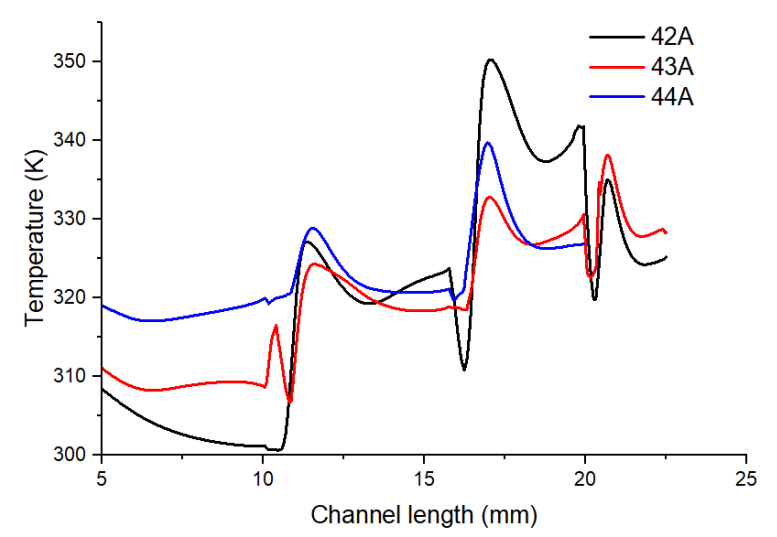

Figure 6: Temperature along the Channel Length.

A number of junps in temperature are visible at certail length it is due to change in thermal boundry lauer and its reinitiation at each bifurcation. Base on obtained data convective coefficients is calculated as shown in figure 7

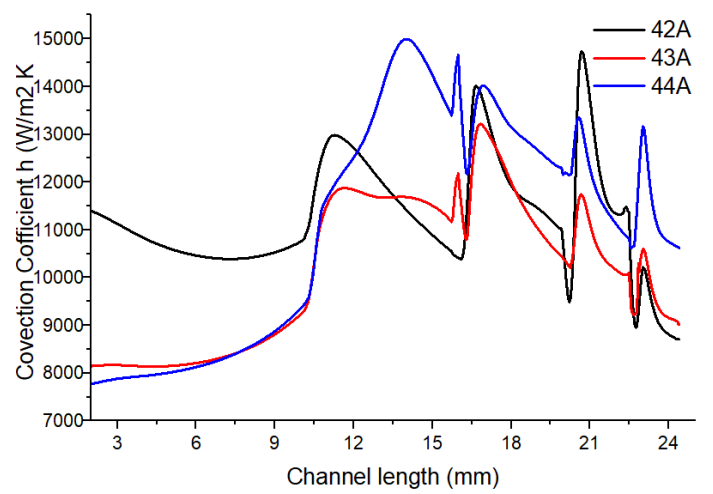

Figure 7: Convective Coefficient along Channel Length.

Nusselts number is highest for smallest inlet plenum size $(2 \mathrm{~mm})$ and is decreasing $8.8 \%$ of the along base channel of K0 level then it regain of 5.8\% of Nu value at entrance of channel base level K0. But for other two models M43A and M44A with larger inlet plenum there is net increase of 11 and $15.9 \%$ for respectively with respect to their respective channel inlet Nusselts numbers. Then there is sudden drop in value of $\mathrm{Nu}$ at the en fog $\mathrm{K} 0$ and it bounce back as flow enters in K1a branch level. Now here again as similar to Reynolds number a different values of Nu are obtain than that of general straight channels. There is decrease in Nusselts number after initial increase of $17 \%$ with respect to branch entrance value of 14 to $1.7 \%$ decreases till the end of branch K1a of M42A.There is net increase in other two k1a branches of M43A and M44A. Specifically largest inlet plenum model M44A observe a huge 57\% increase in Nusselts number with respect to $\mathrm{Nu}$ value at branch entrance. After this level branch low largest Inlet plenums size model observe maximum $\mathrm{Nu}$ value.

\section{CONCLUSIONS AND RECOMMENDATIONS}

In the present study Effect of change in Inlet plenum radius on heat transfer for fractal branched microchannel heat sink is investigated. For constant Aspect ratio of radius of Inlet plenum was varying for laminar flow (Re 2000) .It was concluded that Nusselts number is significantly affected by change in the IP radius. Maximum Nusselts numbers are observed for smallest inlet plenum size in. 


\section{NOMENCLATURE}

- IP = Inlet Plenum

- $\mathbf{A R}=$ Aspect Ratio

- $\mathbf{N u}=$ Nusseltss Number

- H. = Convective Cofficient

- $\mathbf{L}=$ Channel Branch Length

- $\boldsymbol{\beta}=$ Branching Length Ratio

- $\gamma=$ Branching Length Ratio

- $\mathbf{d}=$ Hydraulic Diameter

- $\mathbf{n}=$ Number of Branches Emerging at each Bifurcations

- $\mathbf{R} \quad=$ Radius of Inlet Plenum

- $\mathbf{H} \quad=$ Depth of Channel

- $\mathbf{W} \quad=$ Width od Channel

- $\mathbf{k} \quad=$ Branch Level

- $\quad \mathbf{V} \quad=$ Velocity of Fluid

\section{REFERENCES}

1. D. B. Tuckerman, and R. F. W. Pease, "High performance heat sink for VLSI" IEEE Electron Dev. Let.,(1981), EDL-2, Vol. 5, $126-129$.

2. Poh-Seng Lee, Suresh V.Garimella, Dong Liu,"Investigation of heat transfer in rectangular microchannels" International Journal of Heat and Mass Transfer, (2005), Vol. 48,1688-1704.

3. Weilin Qu, Issam Mudawar,"Experimental and numerical study of pressure drop and heat transfer in a single-phase microchannel heat sink" International Journal of Heat and Mass Transfer, (2002), Vol. 45, 2549-2565

4. Umesh, K. S., V. K. Pravin, and K. Rajagopal. "Experimental Investigation and CFD Analysis of Multi-Cylinder Four Stroke SI Engine Exhaust Manifold for Optimal Geometry to Reduce Back Pressure and to Improve Fuel Efficiency." International Journal of Automobile Engineering Research and Development, 4, 1320 (2014).

5. Geoffrey B. West, James H. Brown, Brian J. Enquist, "A General Model for the Origin of Allometric Scaling Laws in Biology" Science, (1997), Vol. 276, 122-126.

6. J. R. Banavar, A. Maritan, and A. Rinaldo, "Size and Form in Efficient Transportation Networks," Nature,( 1999), Vol. 399, 130-132.

7. Naik, R. T., and C. Nilesh. "Emission characteristic of a high speed diesel engine." International Journal of Mechanical Engineering, 5, 2936 (2016).

8. Gerald E. Miller "Biofluid mechanics and Momentum transport" 
9. D. V. Pence,"Reduced Pumping Power and Wall Temperature in Mi-crochannel Heat Sinks With Fractal-Like Branching Channel Networks," Microscale Thermophys. Eng., (2002) Vol 6, 319-330.

10. A. Bejan, "Constructal Tree Network for Fluid Flow Between a Finite-Size Volume and One Source or Sink," Rev. Gen. Therm., (1997)Vol 36, 592-604.

11. Chen, Y., and Cheng, P., "Heat Transfer and Pressure Drop in Fractal Tree-Like Microchannel Nets," Int. J. Heat Mass Transfer,( 2002), Vol 45, 2643-2648.

12. A. Y. Alharbi, D.V. Pence, R. N. Cullion "Fluid Flow Through Microscale Fractal-Like Branching Channel Networks" Journal of Fluids Engineering (2003), Vol. 125, 1051

13. A. Bejan and M. C. Errara, "Convective Trees of Fluid Channels for Volumetric Cooling" Int. J. Heat Mass Transfer,(2000), vol. 43, 3105-3118.

14. Kassem, TALAL K., et al. "Development of the solar kilns used in drying the palm trees waste in Saudi Arabia." Int. J. Mech. Eng, 2 (2), 4350 (2013).

15. W. Wechsatol,S. Lorente,A. Bejan, “Optimal tree-shaped networks for fluid flow in a disc-shaped body” International Journal of Heat and Mass Transfer. (2002) Vol. 45, 4911-4924.

16. Ampu Harikrishnan, Ms, and Sunita Kumari. "A Study on the Effect of Organizational Culture on Performance Management and Competency Development in a Private University in Himachal Pradesh." International Journal of Research and Analytical: 76.

17. D. Heymann, D.V. Pence, V. Narayanan,"Optimization of fractal-like branching microchannel heat sinks for single-phase flows" Int. J. Therm. Sci. (2010) Vol 49 1383-1393.

18. Joy, N. I. V. I. N. "Design and Analysis of an Integrated Exhaust Manifold with Turbocharger for Considerable Reduction of Over Heating of Bearing System." International Journal of Mechanical and Production Engineering Research and Development 8.2 (2018): 601-608.

19. D.V. Pence, "The simplicity of fractal-like flow networks for effective heat and mass transport" Experimental Thermal and Fluid Science (2010), Vol 34,474-486.

20. S.S.Sehgal ,K. Murugesan, S.K. Mohapatra, "Effect of channel and plenum aspect ratios on the performance of microchannel heat sink under different flow arrangements" Journal of Mechanical Science and Technology(2012) Vol 26, 2985-2994 